\title{
Assessing BESI mobile application usability for caregivers of persons with dementia
}

\author{
Katharine Sourbeer $M D^{\mathrm{a}, *}$ \\ Azziza Bankole MD $\mathrm{D}^{\mathrm{a}, \mathrm{b}, \mathrm{d}}$ \\ Martha Anderson DNP GCNS-BC ${ }^{\mathrm{C}}$ \\ Temple Newbold MSN RN ${ }^{d}$ \\ Rohith Nama MS \\ Marta Belay MSc ${ }^{\mathrm{e}}$ \\ Harshitha Meda MS \\ Tonya Smith-Jackson PhD CPE
}

\begin{abstract}
${ }^{a}$ Virginia Tech Carilion School of Medicine and Research Institute, Roanoke, VA, USA; ${ }^{b}$ Department of Psychiatry \& Behavioral Medicine, Virginia Tech Carilion School of Medicine, Roanoke, VA, USA; 'Department of Interprofessionalism, Virginia Tech Carilion School of Medicine, Roanoke, VA, USA; ${ }^{\mathrm{d} C a r i l i o n}$ Clinic Center for Healthy Aging, Roanoke, VA, USA; ${ }^{\mathrm{e}}$ Department of Industrial \& Systems Engineering, North Carolina A\&T State University, Greensboro, NC, USA; *Corresponding author: knsourbeer@gmail.com
\end{abstract}

K. Sourbeer, A. Bankole, M. Anderson, T. Newbold, R. Nama, M. Belay, H. Meda, T. SmithJackson. Assessing BESI mobile application usability for caregivers of persons with dementia. Gerontechonology 2018;17(2):102-112 https://doi.org/10.4017/gt.2018.17.2.004.00 Introduction This study investigates the usability of an application developed for the Behavioral and Environmental Sensing and Intervention for Dementia Caregiver Empowerment (BESI) study to gather real-time data from caregivers of persons with dementia (PWD). We demonstrate that older adults are willing to try out technology for use in a research setting. This research project ultimately strives to use technology not just in the research setting, but as a tool to support caregivers within their own contexts. Methods The System Usability Scale (SUS) was administered to 30 caregivers in dementia caregiver support groups after participants had completed 5 tasks on a tablet device with Android-based functionality. Revisions were made to the application, such as streamlining the process, eliminating extraneous features, and implementing clock tools. A second phase of SUS testing with a revised BESI app was completed with 15 caregivers. With subsequent BESI deployments, usability data continues to be collected to maximize usability for our target population. Results Thirteen phase 1 respondents scored the application over 70/100 on the SUS, which is the suggested threshold for usability. Eleven phase 2 respondents rated the application 70 and above. A Chi-squared test $\left(\mathrm{X}^{2}(1, \mathrm{~N}=45)=3.62, \mathrm{p}=0.0572\right)$ and an Independent Samples t-test $(\mathrm{t}(43)=-1.84, \mathrm{p}=$ 0.0731 ) were not statistically significant but showed trends toward improvement from phase 1 to phase 2 that may have been significant with a larger sample size. Phase 2 SUS data had $73.3 \%$ of users rating the application usable versus $43.3 \%$ in phase 1 and the mean SUS score increased 10.75 points. Conclusions We conclude that the revised BESI application will be a viable tool for the BESI project. This study also contributes to the rising field of mHealth, particularly regarding its use in an older population.

Keywords: dementia, agitation, caregiver, mHealth, technology

\section{INTRODUCTION}

Alzheimer's dementia (AD) and other forms of dementia are chronic, progressive neurodegenerative disorders, affecting an estimated 5.7 million Americans in 2018 ${ }^{1}$. Many persons with dementia (PWD) are cared for by unpaid caregivers with an estimated 15.9 million caregivers providing $~ 18.4$ billion hours of care in $2017^{1}$. Being a caregiver for a PWD can be both emotionally and physically taxing. Studies have shown that having a partner with dementia corresponds to decreased mental health and reduced life satis- 
faction ${ }^{2}$. Mohamed et al suggest burden is most correlated with severity of psychiatric symptoms, behavioral disturbances, and patients' quality of life $^{3}$. In a survey of care homes, one study found that agitation occurred in $15 \%$ of mild dementia patients and up to $45 \%$ of moderate or severe dementia patients ${ }^{4}$. More agitation was associated with a lower quality of life ${ }^{4}$ and is one of the primary factors prompting institutionalization ${ }^{5-7}$. There are not only social implications to institutionalization but also economic ones; according to Steffancci in 2011, delaying institutionalization can save $\$ 2029$ per month ${ }^{8}$.

This paper describes the use of the System Usability Scale $(\mathrm{S} \cup S)^{9}$ in an older adult population for a tablet application developed for the Behavioral and Environmental Sensing Intervention for Dementia Caregiver Empowerment (BESI) study ${ }^{10}$. The BESI team is a multidisciplinary research team that focuses on the challenges of caregivers of persons living at home with dementia and seeks to implement technology as a tool for the care of older adults. The team consists of clinical healthcare professionals, computer and electrical engineers, and systems engineers, all working together to develop several technologies to improve quality of life of caregivers and PWD. The ultimate goal of BESI is to utilize wearable technology to detect early signs of agitation in PWD living at home, potentially enabling caregivers to intervene early. Previous versions of this wearable technology have been described ${ }^{11,12}$ and a pilot study indicates the Teager energy function can be applied to assess agitation ${ }^{11}$. The use of a body-worn sensor may allow for subtle clues to impending agitation to be detected before it becomes otherwise apparent.

A recent systematic review by Livingston et al found that interventions such as sensory therapies, structured music therapies, communication skills and dementia care mapping (DCM) with supervision, and person-centered care reduced agitation in a care home setting but pointed out a need for data in the communitydwelling setting, as BESI seeks to do. The few studies in the domestic environment included did not find any clear benefit to interventions ${ }^{13}$. However, another systematic review found that for symptomatic and severe agitation, homebased behavioral management techniques and caregiver-based interventions or staff training in communication skills were also effective ${ }^{14}$. Notably, no impacts on quality of life were found, but the studies reporting such outcomes were few $^{13}$. A randomized trial among communitydwelling PWD showed improved outcomes at 4 months with a multi-faceted biobehavioral environmental intervention, although the frequency of agitated behaviors, in particular, was not significant; there were no differences at 9 months but caregivers felt that there were benefits ${ }^{15}$. A study in Taiwan showed that a homebased caregiver training program was effective to decrease problematic behaviors of dementia patients ${ }^{16}$. The BESI study aims to improve on existing studies by utilizing body-worn sensors to better pinpoint times of agitation to allow earlier implementation of intervention techniques.

Recent technological advances have led to the emergence of the field of mHealth, defined by the WHO as "the use of mobile and wireless technologies to support the achievement of health objectives."17 There has been interest in utilizing mHealth in management of dementia. Researchers have delved into the use of mobile applications to help minimize stressful situations for PWD and save caregivers from having to answer repetitive questions, ${ }^{18}$ to provide stimulation for PWD, including the ability of family to send pictures, ${ }^{19}$ to monitor travel in an older person who might get disoriented, ${ }^{20}$ and to target agitation using the tablet directly as the intervention ${ }^{21}$. Most mHealth studies investigating PWD seem to target use of the technology by the PWD, rather than the caregivers, as in this study. Other studies also utilize the tablet to accomplish the end goal whereas BESI employs it as a tool.

One of the challenges facing mHealth and the BESI project is the acceptance of technology by older adults. However, according to the AARP, $89 \%$ of people over age 50 own a mobile device and about half are interested in using mobile technology for their health ${ }^{22}$. Among caregivers, $40 \%$ demonstrated interest in learning more about utilizing technology to help them provide care $^{22}$. A study utilizing community-dwelling Medicare beneficiaries found that $40 \%$ used email or texting and $42.7 \%$ used the internet, with greater use among men, Caucasians, people with a higher education level, married people, and younger people ${ }^{23}$. A study by Grindrod concluded if the mHealth application filled a gap, older adults were both interested in and able to utilize the application ${ }^{24}$. It points out that many applications are not designed with the older population in mind and simple modifications such as large fonts, clear buttons, and high-contrast text may be helpful2 ${ }^{24}$ A focus group produced a set of guidelines regarding technology use in older adults and a series of recommendations including larger targets, simple and meaningful icons, clear navigation, avoidance of scroll bars, and avoidance of irrelevant information on the screen ${ }^{25}$. Training and support are also important aspects when it comes to user rejection or acceptance of new technology ${ }^{26}$. One paper discussed a digital divide, whereby technology can both support the wellbeing of older adults through usage as well as 
Table 1. Demographic information

\begin{tabular}{lcc}
\hline & Phase 1 & Phase 2 \\
\hline Gender & & \\
\hline Male & 4 & 4 \\
\hline Female & 26 & 12 \\
\hline Age & & \\
\hline$>60$ years old & 29 & 13 \\
\hline$<60$ years old & 1 & 3 \\
\hline Race & & \\
\hline Caucasian & 27 & 12 \\
\hline African American & 3 & 1 \\
\hline Hispanic & 0 & \\
\hline
\end{tabular}

harm their wellbeing through isolation and loss of access $^{27}$. Therefore, the exposure of technology provided to older adults in this study may actually prove beneficial in terms of encouraging participants towards the beneficial side of the digital divide. Another study investigated barriers and facilitators to the use of mHealth by older adults in the setting of pain management ${ }^{28}$. Lack of familiarity with technology was a barrier to $31.7 \%$ of participants while training on device use was a facilitator for $61.1 \%$ and equipment tailored to older adults' functional abilities was a facilitator for $34.1 \%{ }^{28}$. The BESI application study might help address the familiarity with technology as a barrier by offering training ahead of time and being designed with older adults in mind. This exposure could help lower barriers of participants to use mHealth technology for other health aspects as well. Cost and concern of battery dying were other notable barriers ${ }^{28}$.

In order to create a model to detect agitation using only wearable technology, sensor agitation data must initially be correlated with known agitation events. The BESI team's system engineers have designed a tablet application for the caregiver to record these events. This is a crucial part in being able to detect agitation solely with the wearable technology and ideally detect it before it would otherwise be apparent. The system would then send real-time notifications to the caregiver to implement appropriate intervention strategies. The tablet application also collects a variety of data regarding mood, sleep, activities, and agitation, providing contextual information that could prove useful to improving quality of life for both caregivers and PWD.

The SUS ${ }^{9}$ was created as a simple tool to assess usability and has subsequently been found to incorporate both measures of usability and learnability ${ }^{29}$. It is a 10 -question Likert scale survey that converts to a score between 0 and 100. It has been found to be highly reliable (AIpha $=0.91)$ and applicable to a wide range of user interface systems ${ }^{30}$. It has the additional advantage of requiring relatively small sample sizes, as low as twelve ${ }^{31}$.

Given the importance of caregiver input via the tablet application in the BESI study, it is essential the caregiver finds the application efficient and easy to use. This paper will discuss the results of a two-phase usability study of the BESI tablet application among PWD caregivers. This study engages older adults in the use of technology to further healthcare goals.

\section{Methods}

Researchers visited local Alzheimer's Association Support Groups for caregivers of PWD. The goals of the BESI project were explained and support group attendees were invited to test out the application. All participants were adults, largely $\geq 60$ years, female, and Caucasian. Minimal demographic data was obtained (Table 1). Participation was voluntary and verbal consent obtained. The study was approved by the Carilion IRB and they approved obtaining verbal consent versus written consent for the support group process. The researchers had three tablets with the BESI app (Figure 1) set out slightly away from the support group and volunteers took turns coming over to test the application while the support group commenced in order to minimize time lost from the normal support group discussion.

\section{Participants were given five task cards:}

(1) We would like you to create your own user account. I have turned on the tablet for you. I will now watch you register as a new user. The name you will use is not your own name. Please use the name "Clara".

(2) Enter information about the person you are caring for. This helps the tablet computer record the information. The name you will use for the person with dementia is "Sarah".

(3) Clara, the caregiver, needs to enter her feelings for the day. This helps the tablet computer keep a log of your stress levels.

(4) The Caregiver (Clara) needs to enter information about her person with dementia (Sarah) based on what has happened that day, especially things like agitation. Select the checkboxes of agitation symptoms that Clara observed in Sarah today.

(5) Enter information about the person with dementia's (Sarah's) sleep quality. This helps the tablet computer find patterns that may link poor sleep to agitation.

Researchers were present to assist and noted areas of confusion, collecting this information as qualitative data provided as verbal reports. When participants completed the tasks, they were asked to complete a modified SUS ${ }^{32}$. Due to the older population, minor phrasing modifications were 


\section{BESI mobille application usabillity}

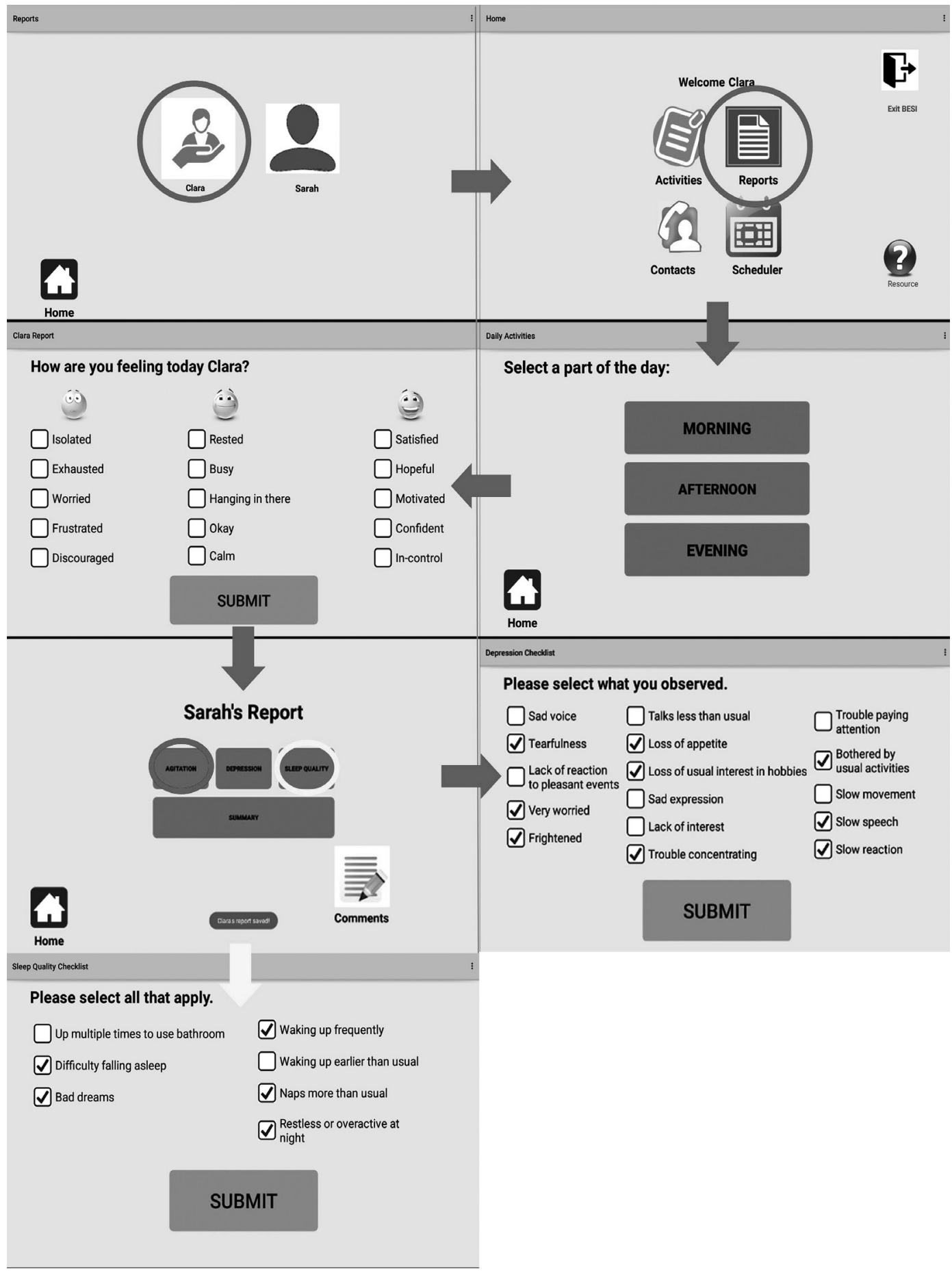

Figure 1. Original BESI application: Circles indicate clicking that button to take you to the next screen, indicated by the arrow of the matching color

made, such as replacing 'system' with 'computer'. Literature suggests minor modifications are appropriate $^{9}$. Questions included in this modified version of original SUS included: (1) I think that I would like to use this computer frequently; (2) I found the computer to be difficult to understand; (3) I thought the computer was easy to use; (4) I think I would need the support of a computer 


\section{BES I mobille application usabillity}

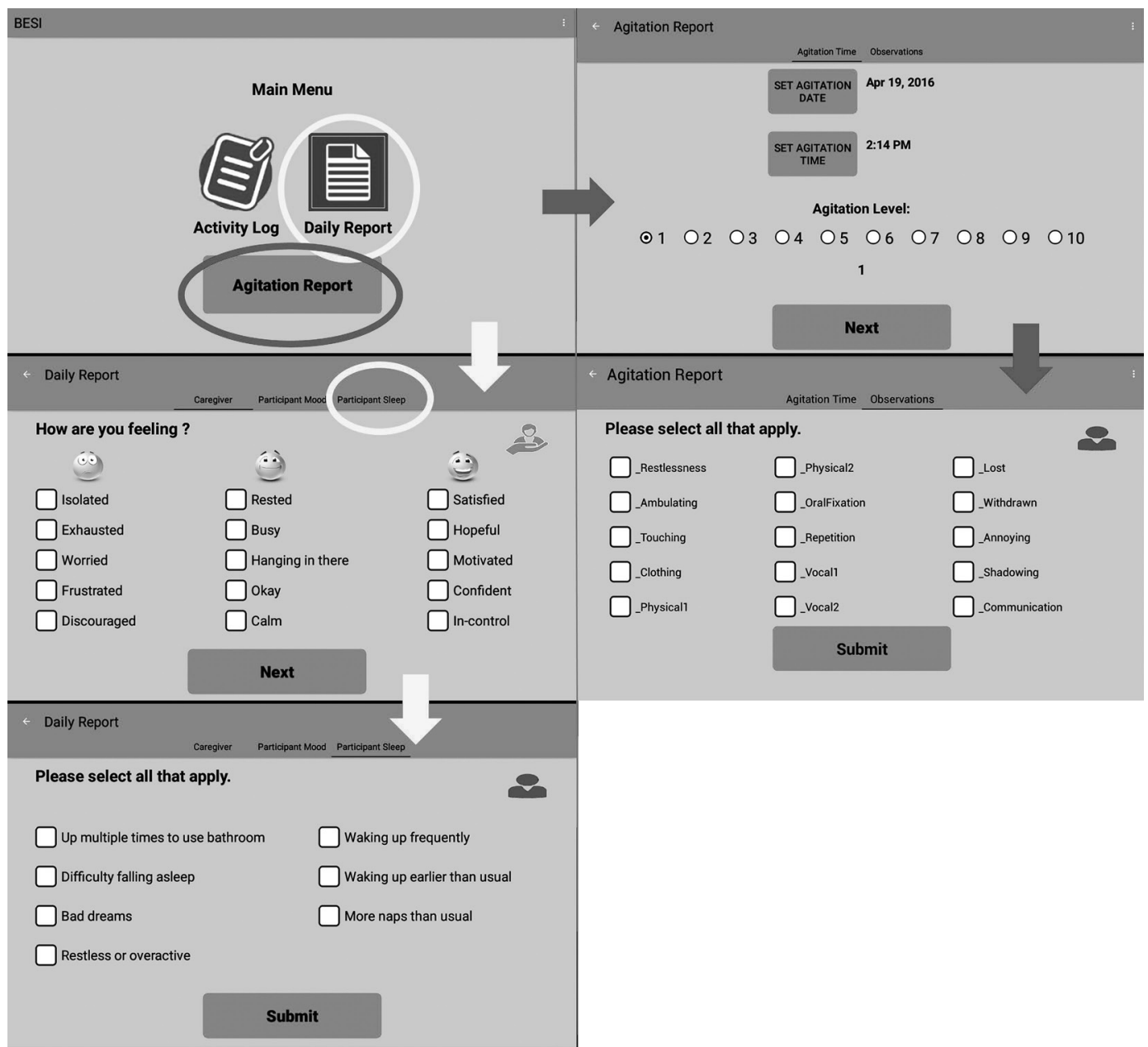

Figure 2. Revised BESI application: Circles indicate clicking that button to take you to the next screen, indicated by the arrow of the matching color

support person to be able to use this computer; (5) I found many functions in this computer were well organized; (6) I thought there was too much confusion with this computer; (7) I would imagine that most people would learn to use this computer very quickly; (8) I found the computer very difficult to use; (9) I felt very confident using the computer; and (10) I needed to learn a lot of things before I could get going with this computer. For each question, it was scaled from 1 (strongly disagree) to 5 (strongly agree).

Based on the observations of the researchers during phase 1 of potential usability problems, the application was modified (Figure 2). A power analysis was conducted after phase 1 to determine what sample size we would need to have $80 \%$ power to detect a significant difference from phase 1. Unfortunately, difficulties finding willing participants limited the sample size in practice. This revised application was tested in a second phase by sixteen caregivers. The task list was modified as follows:
(1) The caregiver needs to set the agitation date, the agitation time, and the agitation level of their person with dementia in the agitation report. This helps the tablet computer to keep the record of when the agitation episode happened and how severe it was.

(2) The caregiver needs to select the observed agitation symptoms that occurred in the agitation episode.

(3) The caregiver needs to enter their feelings in the daily report for the day. This helps the tablet computer to keep a log of the caregivers' stress levels.

(4) Enter the information about the participant's sleep quality from the night before. This helps the tablet computer to find patterns that may link poor sleep to agitation.

(5) The caregiver needs to add the activities of the participant in the activity log and submit it. This helps the tablet computer keep a log of the activities of that particular day.

(6) The caregiver needs to add a new activity in the activity log that is not on the list. This helps 

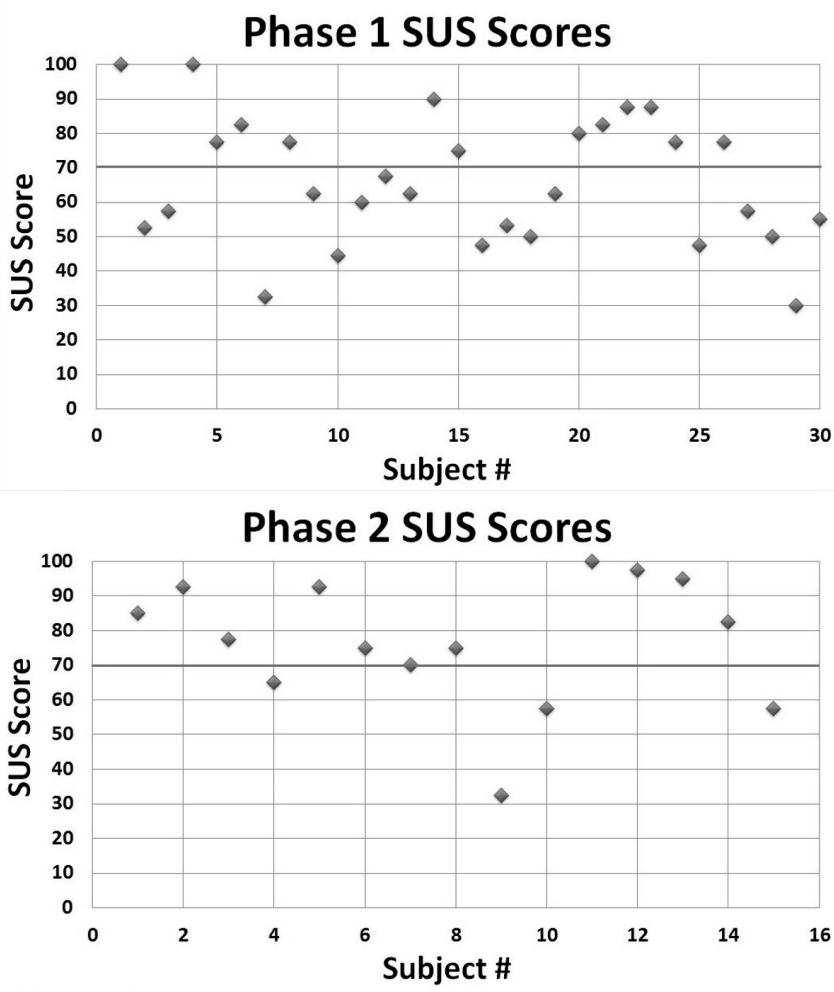

Figure 3. Distribution of SUS scores with a line at the Threshold of Usability (70)

the tablet computer record keep a log of activities specific to the caregiver and the participant.

\section{Results}

Thirty caregivers participated in phase 1 . Sixteen caregivers participated in phase 2, however, only fifteen were included in the analysis as one participated in both phases and this may have influenced the phase 2 score. SUS scores were calculated using the published scoring instructions $^{32}$. The SUS score is derived from the sum of 10 items, each with a possible score range of $0-4$. This leads to a possible overall score range of $0-40$ that is then multiplied by 2.5 to make the SUS more interpretable as a score between 0 and 100. If a participant skipped a question, which was rare, happening only with two subjects, the value was filled in with the mean of the non-missing values after the scale had been adjusted such that all questions were going in the same direction. This was felt to have a negligible

Table 2. Acceptability rating scale

\begin{tabular}{llllll}
\hline Acceptability & Phase $\mathbf{1}$ Frequency & Phase $\mathbf{1} \%$ & Phase 2 Frequency & Phase 2\% \\
\hline Acceptable & 13 & 43.33 & 11 & 73.33 \\
\hline Marginally acceptable & 12 & 40 & 3 & 20 \\
\hline Not acceptable & 5 & 16.67 & 1 & 6.66 \\
\hline
\end{tabular}

impact on the final score as the SUS is a summed score, and when estimated scores were compared to scores generated by excluding the missing data and scaling the sum by a different factor to keep the resultant score between 0 and 100 , scores were nearly identical. Literature suggests that 70 out of 100 is the preferred SUS score threshold for usability ${ }^{30}$. Distribution of scores is shown in Figure 3. The percent of subjects who found the application usable was $43.3 \%$ in phase 1 and $73.3 \%$ in phase 2 . The mean SUS score was 66.25 for phase 1 and 77 for phase 2 .

There many different ways in literature to interpret SUS scores including an acceptability rating scale $^{30}$ (Table 2 \& Figure 4) and an academic grading scale $^{33}$ (Table 3 \& Figure 5). These scales simply provide ways to group the data to make it easier to interpret.

A Pearson chi-square test was performed to compare the percent of subjects who scored the tablet as usable in phase 1 versus phase 2 . The difference between the percentage of participants who rated the application as usable in phase 1 (43.3\%) versus phase 2 $(73.3 \%)$ was nearly statistically significant at the 0.05 level $\left(X^{2}(1, N=45)=3.62, p=0.0572\right)$. While not statistically significant, this is a strong trend towards an association between phase and SUS usability, suggesting the modifications to the application improved its usability. It is possible a larger phase 2 sample size would provide more clarification.

An independent samples t-test was performed to compare the mean SUS in phase 1 versus phase $2(\mathrm{t}(43)=-1.84, \mathrm{p}=0.0731)$. This was also not quite statistically significant but showed a trend towards improvement with an increase in the mean from phase 1 to phase 2 of 10.75 points. The fact that the sample size in phase 2 was smaller than the sample size in phase 1 may have adversely affected the ability to detect a significant difference. Because the sample sizes for phase 1 and phase 2 were unequal, we ran the Folded $\mathrm{F}$ test, $F(29,14)=1.00$, $p=1.0$. Since the folded $F$ was not significant with a p-value of 1.0 we 
Table 3. Academic grading scale

\begin{tabular}{lllll}
\hline Grade & Phase 1 Frequency & Phase 1\% & Phase 2 Frequency & Phase 2\% \\
\hline A & 3 & 10 & 5 & 33.33 \\
\hline B & 5 & 16.67 & 2 & 13.33 \\
\hline C & 5 & 16.67 & 4 & 26.67 \\
\hline D & 5 & 16.67 & 1 & 6.67 \\
\hline F & 12 & 40 & 3 & 20 \\
\hline
\end{tabular}

\section{Discussion}

Based on the responses from our presentations to support groups, overall interest in the project as a whole was high, but many caregivers expressed reservations about technology. Debriefing after support groups included researchers collecting comments and responses. We con-

did not need to utilize the Satterthwaite solution.

Qualitative data collected during the testing and the solutions are described in Table 4 for phase 1 and Table 5 for phase 2. Of note, most phase 2 issues are with the process, not the application design; this will be addressed by more comprehensive instructions for caregivers at BESI deployment. This includes a demonstration of each button and section, a chance for them to go through each page themselves, and an opportunity to ask questions. The generic choices of vocal and physical agitation episode observations in the tablet application (Figure 2) will be set with words selected by each caregiver, specific to their PWD, prior to deployment. clude that the initial BESI application needed significant revision, but that it showed promise as a valid study tool. Since the SUS was originally designed as a 'quick and dirty' way to assess a product's usability, the intended interpretation was simply a score out of $100^{32}$. This score is not a percentage; the scale is out of 100 because it allowed for easy interpretation. Literature suggests the threshold for usability is a score of $70^{30}$. Overall it did not quite meet acceptability in phase 1 , but results were promising that significant revisions would improve it to meet usability expectations. Although the difference in the proportion of subjects finding the application usable between the two phases was not statistically significant, there was a trend towards significance with a change from $43.3 \%$ to $73.3 \%(p=0.0572)$, sug-

Table 4. Phase 1: Qualitative data

\begin{tabular}{|c|c|c|}
\hline$\overline{\text { Task }}$ & Issue & Solution \\
\hline 1: Enter name & $\begin{array}{l}\text { Technical issue where the keyboard } \\
\text { covered buttons }\end{array}$ & Application redesigned to fix \\
\hline $\begin{array}{l}\text { 2: Enter PWD } \\
\text { name }\end{array}$ & Confusion about made-up names & N/A for real deployment \\
\hline \multirow[t]{4}{*}{$\begin{array}{l}\text { 3: Enter caregiver } \\
\text { 'feelings' }\end{array}$} & $\begin{array}{l}\text { Unsure which icon to navigate. Some } \\
\text { appropriately guessed 'reports,' others } \\
\text { 'activities.' }\end{array}$ & $\begin{array}{l}\text { Testers received no prior instruction, but caregivers will. } \\
\text { Unnecessary icons, such as the calendar, have been } \\
\text { eliminated to minimize confusion. }\end{array}$ \\
\hline & Can I check more than one 'feeling'? & Instructions added to 'check all that apply.' \\
\hline & $\begin{array}{l}\text { Confusion over which 'feelings' report } \\
\text { was for the caregiver versus PWD }\end{array}$ & Function of made-up names, N/A for real deployment \\
\hline & Not labeled well & Streamlining to clarify labeling \\
\hline \multirow[t]{4}{*}{$\begin{array}{l}\text { 4: Enter 'agitation } \\
\text { report' }\end{array}$} & Agitation not a problem with their PWD & $\begin{array}{l}\text { During deployment, caregivers only enter 'agitation' when } \\
\text { applicable }\end{array}$ \\
\hline & \multicolumn{2}{|c|}{ Went into the 'depression' section insteadlnstructions for deployment } \\
\hline & Options presented were too severe & $\begin{array}{l}\text { Wording designed to line up with the Cohen-Mansfield } \\
\text { Agitation Index }{ }^{35}\end{array}$ \\
\hline & $\begin{array}{l}\text { Some filled out all categories in the } \\
\text { 'reports' section rather than just agitation }\end{array}$ & $\begin{array}{l}\text { Caregivers will be instructed at deployment regarding which } \\
\text { reports to fill out when---they should fill out all reports three } \\
\text { times a day and the agitation report as needed for agitation } \\
\text { episodes. }\end{array}$ \\
\hline
\end{tabular}

\begin{tabular}{lll}
\hline 5: Enter 'sleep & $\begin{array}{l}\text { Some filled out all categories in the } \\
\text { 'reports' section rather than just sleeping }\end{array}$ & Caregivers will be instructed regarding which reports to fill out \\
quality' & 'ren
\end{tabular}
quality' 'reports' section rather than just sleeping and when

\begin{tabular}{ll}
\hline General & Request to free text
\end{tabular}$\quad \begin{aligned} & \text { This will be an option in the 'activities' section, however, for } \\
& \text { agitation descriptors we are limiting extraneous free text data. }\end{aligned}$

Concern that most people were older and Attempted to make the application as user-friendly as possible not computer savvy for this population 


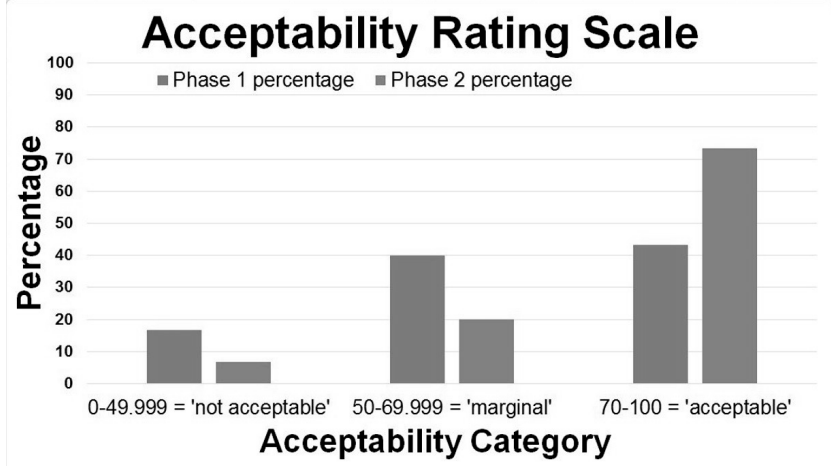

Figure 4. SUS scores by acceptability rating scale to detect a difference in the unlikely event that the revisions made the application significantly worse.

Researchers worked with consumers before the real study was launched to clarify terminology and acceptability, thus recognizing the intellectual merit and experience of the older consumers. Thus, we focus on the process of involving study participants from the very beginning. During recruitment for the larger BESI study, the clinical team also continues to engage with each caregiver to gather data on acceptability, get suggestions for imgesting a possible improvement. The difference between the means of the two phases was not quite significant $(p=0.0731)$, but there was a 10.75 point increase in mean SUS score. Both of these findings suggest improvement from phase 1 to phase 2, but with p-values of 0.0572 and 0.0731 , the improvement may be due to chance rather than the revisions. The small sample size in phase 2 likely contributed to a lack of statistical significance; repeating the study with a larger sample size would probably provide more information. In the power analysis conducted prior to phase 2 testing, given that $43.3 \%$ of phase 1 participants found the application usable with a score 70 or above, a sample size of 15 in phase 2 would have required $79 \%$ of respondents to rate the application as usable. If the sample size had been 21 in phase 2 , the difference between the $43.3 \%$ in phase 1 and the $73.3 \%$ found in phase 2 would have been significant. Unfortunately, not as many subjects were found for phase 2 as hoped and therefore the sample size was less than ideal.

Nonetheless, from a clinical standpoint, the improvements suggest that the BESI application is a useful and viable tool. It is possible that utilizing a one-tailed test might have been a good option that may have yielded a statistically significant p-value; however, such a test would have failed

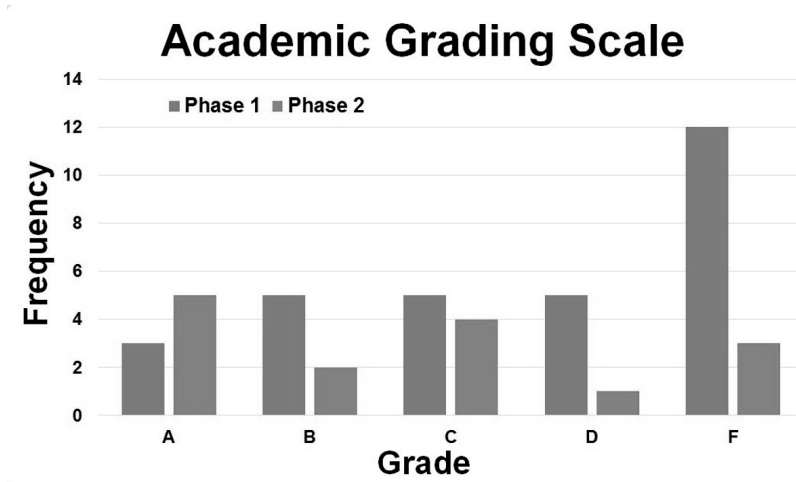

Figure 5. Graph of SUS scores by academic grading scale provements, listen to frustrations, and continuthroughout the research process.

\section{Revisions for Phase 2}

The initial design of BESI incorporated many of the recommendations for older users. For example, the lavender background color was chosen as a color light enough to provide high contrast with text, but not pure white, which is not recommended ${ }^{25}$. For phase 2, a number of changes were made to streamline application. For example, there are fewer tabs and it is easier to navigate. Rather than having to go back to a main screen within each report section, the user now has tabs at the top of the screen, eliminating this extra step (Figure 2). We also eliminated the screen where subjects had to pick whether they wanted to fill out information on the caregiver or PWD (Figure 1) and simply specify that information in separate tabs. While we suspect confusion related to this screen was rooted in the made-up caregiver and PWD names used for testing, we felt additional streamlining would be beneficial. We have also minimized features causing confusion, such as swiping to get to the next screen. Clock tools have been implemented to make it easier to record times for agitation episodes and activities. The application now saves activities that the caregiver enters so it is easier to add a daily activity without re-typing it. We also eliminated extraneous features, such as the calendar, to make things simpler. Although we believe that the second version of the application is much better, providing a simpler, more user-friendly interface, there was no statistical difference detected between the two versions. As anticipated, phase 2 testing demonstrates that these changes will allow the application to serve as a useful tool in the BESI study.

\section{Limitations}

There was limited demographic variation; most participants were older Caucasian women. Minimal demographic ally verify the merit of working with the subjects 
Table 5. Phase 2: Qualitative data

\begin{tabular}{|c|c|c|}
\hline Task & Issue & Solution \\
\hline \multirow[t]{2}{*}{ 1: Agitation level } & $\begin{array}{l}\text { Unclear navigation tried other options such as activity log } \\
\text { and daily report first }\end{array}$ & Instructions for deployment \\
\hline & Unclear how to rate $1-10$ & Instructions for deployment \\
\hline 2: Agitation symptoms & Add sobbing or tearing up & $\begin{array}{l}\text { Tablet will be pre-loaded with } \\
\text { words specific for each PWD }\end{array}$ \\
\hline 3: Caregiver feelings & Confusion over whether caregiver or PWD & Instructions for deployment \\
\hline 4: Sleep Quality & None noted & $\mathrm{n} / \mathrm{a}$ \\
\hline 5: Activity Log & None noted & $\mathrm{n} / \mathrm{a}$ \\
\hline \multirow[t]{3}{*}{ 6: New activity } & Edit button to fix spelling? & $\begin{array}{l}\text { As long as we can tell what the } \\
\text { activity is, spelling is not an issue. }\end{array}$ \\
\hline & $\begin{array}{l}\text { After adding a new activity you still have to check off and } \\
\text { submit it }\end{array}$ & Instructions for deployment \\
\hline & $\begin{array}{l}\text { Confusing because after adding the new activity the others } \\
\text { weren't checked as they had already been submitted but the } \\
\text { tendency would be to check them again }\end{array}$ & Instructions for deployment \\
\hline \multirow[t]{3}{*}{ General } & Display day of week, date, and time on home page & Consider for future \\
\hline & $\begin{array}{l}\text { Indicate whether it's the } 1^{\text {st }}, 2^{\text {nd }} \text {, or } 3^{\text {rd }} \text { time filling out the } \\
\text { report that day }\end{array}$ & Consider for future \\
\hline & Make it more obvious how to go back & Instructions for deployment \\
\hline
\end{tabular}

data were collected for this study. Given the limited pool of caregivers in support groups, the sample size for phase 2 testing was smaller than desired.

\section{Conclusions}

We conclude that when involved in the process, older adults can do well with technology. In this study, we modified our application based on what we observed people having trouble with and their qualitative feedback. These revisions to the BESI application between phases 1 and $2 \mathrm{im}$ proved the usability of the application from $43.3 \%$ finding it usable in phase 1 to $73.3 \%$ of users in phase 2, although this difference only trended towards statistical significance. The application has now been used in the home setting for the BESI project. Post-deployment usability testing is also being undertaken in order to continually refine the application. Thus, we conclude that the BESI tablet application is a viable and vital tool to utilize in the BESI study as it provides researchers a narrative of events that can be linked to the wearable technology data. More importantly, we have demonstrated that older adults are willing to try out technology for use in a research setting. This research project ultimately strives to use technology not just in the research setting, but as a tool to help caregivers. BESI represents an interprofessional team working with clinicians and engineers to develop technology that is both acceptable and helpful to caregivers. According to a survey of people 60 years old and up by the AARP, approximately $90 \%$ of seniors plan to continue living in their current homes for the next five to ten years ${ }^{34}$. Recognizing that most older adults prefer to stay in their own homes, BESI strives for caregiver empowerment.

By linking the known agitation events captured by the tablet application with wearable technology data, we can learn what movement data corresponds to agitation episodes. Once the wearable technology is able to recognize agitation episodes, the caregiver will receive real-time alerts that agitation episodes may be forthcoming. Beyond the tablet application, BESI will also utilize environmental sensors to see if those play a role in a given PWD's agitation. Hopefully, this warning will come early enough that the caregiver can implement management techniques to try to stave off the agitation episodes. These interventions may vary per PWD but could include things such as calming music or walking. The application also provides information about mood, sleep, and daily activities, which could help inform patterns between these variables and agitation episodes. The ultimate goal for this application, in conjunction with the BESI sensor technology, is to help improve caregivers' ability to cope with agitation and improve quality of life for both the PWD and the caregiver. Crucial to the realization of this goal is the willingness of caregivers, mostly of an older population, to utilize this technology for that purpose. When engaged and involved in the process, caregivers have shown a willingness and interest in doing so.

This application also offers possibilities for further research. Even without correlation to the wearable technology utilized in BESI, the data captured by the tablet could provide valuable information about caregiver and PWD emotional well-being, sleep quality, and day-to-day activities. As de- 
scribed earlier in this paper, there are numerous mobile applications aimed at PWD and this application has the potential to be an important additional tool on a tablet dedicated to dementia management. This study marks a step in the development of a process for how to engage and involve older adults in the use of technology.

\section{Acknowledgements}

We would like to thank the BESI Research Team for all of their hard work and creating the application software. Particularly, thanks to Ridwan Alam, Joshua Dugan, Nutta Homdee, Neeraj Gandhi, Ben Ghaemmaghami, Jiaqi Gong, and Professor John Lach for their role in the broader study and the development of the tablet application, thanks to Katherine Shaver for her work on the statistics, and thanks to the BESI study participants for their willingness to be involved. This project is supported in part by the National Science Foundation under grant IIS-1418622 and presented at the Psychiatric Society of Virginia Fall Meeting in October 2016 in Roanoke, VA.

\section{References}

1. Alzheimer's Association Alzheimer's Disease Facts and Figures. Alzheimer's Association;2016

2. Ask H, Langballe EM, Holmen J, Selbaek G, Saltvedt I, Tambs K. Mental health and wellbeing in spouses of persons with dementia: the Nord-Trondelag Health Study. BMC Public Health. 2014;14:413; https://doi.org/10.1186/1471-2458-14-413

3. Mohamed S, Rosenheck R, Lyketsos CG, Schneider LS. Caregiver burden in Alzheimer disease: crosssectional and longitudinal patient correlates. The American journal of geriatric psychiatry : official journal of the American Association for Geriatric Psychiatry. 2010;18(10):917-927; https://doi. org/10.1097/JGP.0b013e3181d5745d

4. Livingston G, Barber J, Marston L, Rapaport P, Livingston D, Cousins S, Robertson S, La Frenais F, Cooper C. Prevalence of and associations with agitation in residents with dementia living in care homes: MARQUE cross-sectional study. BJPsych Open. 2017;3(4):171-178; https://doi.org/10.1192/ bjpo.bp.117.005181

5. Sansoni J, Anderson KH, Varona LM, Varela G. Caregivers of Alzheimer's patients and factors influencing institutionalization of loved ones: some considerations on existing literature. Ann Ig. 2013;25(3):235246; https://doi.org/10.7416/ai.2013.1926

6. Steele C, Rovner B, Chase GA, Folstein M. Psychiatric symptoms and nursing home placement of patients with Alzheimer's disease. The American journal of psychiatry. 1990;147(8):1049-1051; https://doi.org/10.1176/ajp.147.8.1049

7. Buhr GT, Kuchibhatla M, Clipp EC. Caregivers' reasons for nursing home placement: clues for improving discussions with families prior to the transition. The Gerontologist. 2006;46(1):52-61

8. Stefanacci RG. The costs of Alzheimer's disease and the value of effective therapies. Am J Manag Care. 2011;17 Suppl 13:S356-362

9. Brooke J. SUS: A Retrospective. Journal of Usability Studies. 2013;8(2):29-40

10. Alam RD, Joshua; Homdee, Nutta; Gandhi, Neeraj; Ghaemmaghami, Ben; Meda, Harshitha; Bankole,
Azziza; Anderson, Martha S.; Gong, Jiaqi; SmithJackson, Tonya; Lach, John. BESI: Reliable and Heterogeneous Sensing and Intervention for In-Home Health Applications. IEEE International Conference on Connected Health: Applications, Systems and Engineering Technologies; 2017.

11. Bankole A, Anderson M, Smith-Jackson T, et al. Validation of noninvasive body sensor network technology in the detection of agitation in dementia. American Journal of Alzheimer's Disease and other Dementias. 2012;27(5):346-354. https://doi. org/10.1177/1533317512452036

12. Barth AT, Hanson MA, Powell HCJ, Lach J. TEMPO 3.1: A Body Area Sensor Network Platform for Continuous Movement Assessment. International Conference on Body Sensor Networks; 2009

13. Livingston G, Kelly L, Lewis-Holmes E, Baio G, Morris S, Patel N, Omaz RZ, Katona C, Cooper C. A systematic review of the clinical effectiveness and cost-effectiveness of sensory, psychological and behavioural interventions for managing agitation in older adults with dementia. Health Technol Assess. 2014;18(39):1226, v-vi; https://doi.org/10.3310/hta18390

14. Abraha I, Rimland JM, Trotta FM, Dell'Aquila G, Cruz-Jentoft A, Petrovic M, Gudmundsson A, Soiza R, O'Mahony D, Guaita A, Cherubini A. Systematic review of systematic reviews of non-pharmacological interventions to treat behavioural disturbances in older patients with dementia. The SENATOROnTop series. BMJ Open. 2017;7(3):e012759; https://doi.org/10.1136/bmjopen-2016-012759

15. Gitlin LN, Winter L, Dennis MP, Hodgson N, Hauck WW. A biobehavioral home-based intervention and the well-being of patients with dementia and their caregivers: the COPE randomized trial. JAMA. 2010;304(9):983-991; https://doi.org/10.1001/jama.2010.1253

16. Huang HL, Shyu YIL, Chen MC, Chen ST, Lin LC. A pilot study on a home-based caregiver training program for improving caregiver self-efficacy and decreasing the behavioral problems of elders with dementia in Taiwan. International journal of geriatric psychiatry. 2003;18(4):337-345; https://doi. org/10.1002/gps.835

17. mHealth: New horizons for health through mobile technologies. World Health Organization 2011

18. Navarro R, Favela J. Usability assessment of a pervasive system to assist caregivers in dealing with repetitive behaviors of patients with dementia. Paper presented at: 4th International Conference on pervasive technologies related to assistive environments 2011; Greece

19. Yamagata C, Kowtko M, Coppola J. Mobile app development and usability research to help dementia and Alzheimer patients. Paper presented at: 2013 IEEE Long Island Systems, Applications and Technology Conference (LISAT)2013

20. Xiao B, Asghar MZ, Jamsa T, Pulli P. "Canderoid": A 
mobile system to remotely monitor travelling status of the elderly with dementia. Paper presented at: 2013 International Joint Conference on Awareness Science and Technology \& Ubi-Media Computing (iCAST 2013 \& UMEDIA 2013)2013

21. Vahia IV, Kamat R, Vang C, et al. Use of Tablet Devices in the Management of Agitation Among Inpatients with Dementia: An Open-Label Study. The American journal of geriatric psychiatry : official journal of the American Association for Geriatric Psychiatry. 2016; https://doi.org/10.1016/j.jagp.2016.07.011

22. Barrett L. Health and Caregiving Among the 50+: Ownership, Use and Interest in Mobile Technology. Washington, D.C.: American Association of Retired Persons; 2011

23. Gell NM, Rosenberg DE, Demiris G, LaCroix AZ, Patel KV. Patterns of technology use among older adults with and without disabilities. The Gerontologist. 2015;55(3):412-421; https://doi.org/10.1093/ geront/gnt166

24. Grindrod KA, Li M, Gates A. Evaluating user perceptions of mobile medication management applications with older adults: A usability study. JMIR Mhealth Uhealth. 2014;2(1):e11; https://doi. org/10.2196/mhealth.3048

25. Zaphiris P, Ghiawadwala M, Mughal S. Age-centered Research-Based Web Design Guidelines. CHI; 2005; Portland, OR

26. Barnard Y, Bradley MD, Hodgson F, Lloyd AD. Learning to use new technologies by older adults: Perceived difficulties, experimentation behaviour and usability. Computers in Human Behavior. 2013;29(4):1715; https://doi.org/10.1016/j.chb.2013.02.006

27. Hill R, Betts LR, Gardner SE. Older adults' experi- ences and perceptions of digital technology: (Dis) empowerment, wellbeing, and inclusion. Computers in Human Behavior. 2015;48:415-423; https:// doi.org/10.1016/j.chb.2015.01.062

28. Parker SJ, Jessel S, Richardson JE, Reid MC. Older adults are mobile too!ldentifying the barriers and facilitators to older adults' use of mHealth for pain management. BMC Geriatr. 2013;13:43; https://doi. org/10.1186/1471-2318-13-43

29. Borsci S, Federici S, Lauriola M. On the dimensionality of the System Usability Scale: a test of alternative measurement models. Cogn Process. 2009;10(3):193197; https://doi.org/10.1007/s10339-009-0268-9

30. Bangor A, Kortum P, Miller J. An Empirical Evaluation of the System Usability Scale. International Journal of Human-Computer Interaction. 2008;24(6):574594; https://doi.org/10.1080/10447310802205776

31. Tullis TS, Stetson JN. A Comparison of Questionnaires for Assessing Website Usability. Usability Professionals Association (UPA); 2004; Minneapolis, Minnesota

32. Brooke J. SUS: a 'quick and dirty' usability scale. In: Jordan PW TB, Weerdmeester BA, McClelland IL, ed. Usability Evaluation in Industry. London: Taylor and Francis; 1996:189-194

33. Bangor A, Kortum P, Miller J. Determining What Individual SUS Scores Mean: Adding an Adjective Rating Scale. Journal of Usability Studies. 2009;4(3):114-123

34. The United States of Aging Survey. AARP;2012

35. Cohen-Mansfield J, Marx MS, Rosenthal AS. A description of agitation in a nursing home. Journal of gerontology. 1989;44(3):M77-84 